\begin{tabular}{|c|c|c|}
\hline 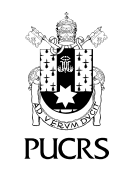 & $\begin{array}{l}\text { ESCOLA DE } \\
\text { HUMANIDADES }\end{array}$ & $\begin{array}{l}\text { Revista Digital do Programa de Pós-Graduação em Letras da PUCRS } \\
\text { Letrônica, Porto Alegre, v. 13, n. 1, p. 1-10, jan.-mar. } 2020 \\
\text { e-ISSN: } 1984-4301\end{array}$ \\
\hline do) $\mathrm{http}: / / \mathrm{dx}$ & $\mathrm{rg} / 10.15448 / 1984-4301.2020 .1 .35113$ & \\
\hline
\end{tabular}

\title{
De Josefina Bórquez a Jesusa Palancares: do individual ao coletivo em Hasta no verte Jesús Mío
}

\author{
From Josefina Bórquez to Jesusa Palancares: from the \\ personal to the collective in Hasta no verte Jesús Mio \\ De Josefina Bórquez a Jesusa Palancares: de lo individual \\ a lo Colectivo en Hasta No Verte Jesús Mio
}

\author{
Mariana Marise \\ Fernandes Leite ${ }^{1}$ \\ orcid.org/0000-0003-4835-8995 \\ marifleite@gmail.com
}

Recebido em: 29 jul. 2019.

Aprovado em: 18 nov. 2019

Publicado em: 7 abr. 2020

\section{(c) (i)}

Artigo está licenciado sob forma de uma licença Creative Commons Atribuição 4.0 Internacional.
Resumo: O presente trabalho propõe analisar a obra Hasta no verte Jesús Mio (1969), de Elena Poniatowska, apontando como se dá a passagem da experiência individual à experiência coletiva por meio da narração e que impacto tal ocorrência provoca na interpretação da obra. Para tal fim, aprecia-se o texto, evidenciando a possibilidade de a personagem deixar de ser um sujeito individualizado para ser uma marca e apontando o texto como uma forma de questionar não só a realidade que representa, mas também a própria noção de literatura que o tem colocado em xeque quanto a seu valor. Para melhor embasar os apontamentos acerca das noções de experiência, são utilizadas destacadamente as considerações de Ana Costa, em "Da representação social da memória" (2001), de Florencia Garramuño, em La experiencia opaca (2009) e de Beatriz Sarlo, em "Crítica do testemunho: sujeito e experiência" (2007). Servem como apoio teórico que sustenta o recorte escolhido Rita Terezinha Schimidt (2012), Ricardo Reis (1992), Lizandro Carlos Calegari (2012) Josefina Ludmer (2013) e Walter Benjamin (1985). Palavras-chave: Elena Poniatowska - Hasta no verte Jesús Mio. Cânone. Experiência. Do individual ao coletivo.

Abstract: This paper proposes to analyze Elena Poniatowska's Hasta no verte Jesús Mio (1969), pointing out how the passage from the personal experience to the collective experience through the narrative occurs and the impact it provokes in the interpretation of this work. To this end, the text is appreciated, evidencing the possibility of the character stop being an individualized subject to start being a symbol and pointing the text as a form of questioning not only the reality that it represents but also the very notion of literature that has put its value in check. For better support of the points given about these notions of experience, the considerations of Ana Costa in "Da representação social da memória" (2001), of Florencia Garramuño in La experiencia opaca (2009) and of Beatriz Sarlo in "Critica do testemunho: sujeito e experiência" (2007) are used prominently. Rita Terezinha Schimidt (2012), Ricardo Reis (1992), Lizandro Carlos Calegari (2012), Josefina Ludmer (2013) and Walter Benjamin (1985) are used as theoretical support. Keywords: Elena Poniatowaska - Hasta no verte Jesús Mio. Canon. Experience. From the personal to the collective.

Resumen: El presente texto propone analizar Hasta no verte Jesús mio, de Elena Poniatowska, señalando como ocurre el paso de la experiencia individual a la colectiva por medio de la narración y qué efecto ese suceso produce en la interpretación de la obra. Para ese fin, se observa el texto, poniendo en relieve la posibilidad de que el personaje no sea más una individualidad, sino una marca señalando la obra como una manera de cuestionar la realidad y además de cuestionar la noción propia de literatura, noción, poniendo en tela de juicio el valor del texto de Poniatowska en análisis. Son base para las consideraciones acerca de la noción de experiencia los apuntes de Ana Costa, en "Da representação social da memoria" (2001), de Florencia Garramuño, en La experiencia opaca (2009) y de Beatriz Sarlo, em "Crítica do testemunho: sujeito e experiencia" (2007). Apoyan teóricamente el recorte seleccionado Rita Terezinha Schimidt (2012), Ricardo Reis 
(1992), Lizandro Carlos Calegari (2012) Josefina Ludmer (2013) y Walter Benjamin (1985).

Palabras clave: Elena Poniatowaska - Hasta no verte Jesús Mio. Canon. Experiencia. De lo individual a lo colectivo.

\section{Introdução}

"Esta es la tercera vez que regreso a la tierra, pero nunca había sufrido tanto como en esta reencarnación ya que en la anterior fui reina" (PONIATOWSKA, 1985, p. 9). Assim tem início Hasta no Verte Jesús Mio, publicado pela primeira vez em 1969, de Elena Poniatowska. Uma narração em que a personagem protagonista, Jesusa Palancares, narra em primeira pessoa, a história de sua vida desde os primeiros anos de existência, ocorrida antes da revolução mexicana de 1910, até meados do século, quando a narrativa se encerra.

O livro tem como base, segundo Cynthia Steele (1992, p. 157-158) uma série de entrevistas orais concedidas semanalmente, no percurso de um ano, a Elena Poniatowska por Josefina Bórquez. Elena e Josefina haviam-se conhecido, de acordo com Michael K. Schuessler, em Elenisima: Ingenio y figura de Elena Poniatowska ([2017]), na primeira metade da década de 1960, enquanto a autora fazia entrevistas a um grupo de presidiários para a escrita de outra de suas obras, Todo empezó al domingo, que seria publicada em 1963. A autora e Josefina Bórquez se encontraram pela primeira vez então nas vizinhanças do então espaço de trabalho de Poniatowska.

Bórquez era uma mexicana de Oaxaca, nascida nos primeiros anos do século XX. A oaxaquenha viveu a experiência histórica da Revolução Mexicana de 1910 nos primeiros anos de sua vida. Após um periodo em que participou ativamente da Revolução, a mulher experienciou a vida adulta em um México impactado social e politicamente pelo levante.

Aentrevistada mostra uma realidade totalmente distinta daquela vivida por Poniatowska, que demonstra não ter contato com as condições da pobreza absoluta experimentadas por milhões de mulheres e homens. É o que se pode constatar no seguinte trecho de Luz y Luna, las Lunitas:

De la mano de Jesusa entré en contacto con la pobreza, la de deveras, la del agua que se recoge en cubetas y se lleva cuidando de no tirarla, la de la lavada sobre la tablita de lámina porque no hay lavadero, la de la luz que se roba por medio de "diablitos", la de las gallinas que ponen huevos sin cascarón, "no más la pura tecata" porque la falta de sol no permite que se calcifiquen. Jesusa pertenece a los millones de hombres y mujeres que no viven, sobreviven. El sólo atravesar el dia y llegar hasta la noche les cuesta tantísimo trabajo que las horas y la energía se les van en eso que para los marginados resulta tan dificil: ganarse la vida, como se la vida fuese una mercancia más, permanecer a flote, respirar tranquilos, aunque sólo sea un momento, al atardecer. cuando las gallinas ya no chistan tras de su alambrada y el gato se despereza sobre la tierra aprisionada (PONIATOWSKA, 2001, p. 13).

Como indica o trecho, a entrevistadora é impactada pela vivência da entrevistada. Essa vivência transparece também em Hasta no verte Jesús Mío, uma vez que os acontecimentos narrados nas entrevistas concedidas por Bórquez à jornalista são apresentados de maneira bastante fiel pela narração escrita de Poniatowska. No entanto, ainda que a linguagem utilizada por Bórquez seja bastante preservada, a própria autora admite a interferência da sua escrita na reconstrução da realidade, como comprova a seguinte afirmação, citada por Cynthia Steele, em "Testimonio y autor/ idad en 'Hasta no verte Jesús mío':

[...] utilicé las anedoctas, las ideas y muchos de los modismos de Jesusa Palancares, pero no podria afirmar que el relato es una transcripción directa de su vida, porque ella misma lo rechazaria. Maté a los personajes que me sobraban, eliminé cuanta sección espiritualista pude, elaboré donde me pareció necesario, podé, cosí, remendé, inventé (STEELE, 1992, p. 158).

Dessa forma, constata-se que a escrita de Hasta no Verte Jesús Mío provoca uma multiplicidade de posicionamentos sobre sua natureza, sobre sua relação com a literatura e sobre sua relação com o real. Esses argumentos ora apelam para sua estrutura, ora para a natureza de sua inspiração, ora para sua relação com a História e com a linguagem.

\section{Considerações sobre a literariedade do texto}

Há apontamentos que direcionam sua relação com a novela testimonial de Miguel Barnet (SKLODOWSKA, 2019), para o bildungsroman 
(ALBIN, 2008) e há apontamentos ainda em direção a outros caminhos, como o testimonio feminino.

No artigo "Hasta no verte Jesús mío: la voz del otro, voz propia" (2007), Daniel Orizaga Doguim, em citação de Nagi Zekmi, aponta que o texto de Poniatowska foi inicialmente indicado como testimonio femenino, uma vez que

se ofrece por una (varias) mujer(es) marginada(s), cuyos derechos individuales y/o grupales han sido violados u que vive para representar ese grupo introduciéndose en el mundo académico, a veces, a través de la relación con un intelectual (antropólogo/a, escritor/a, etc.) que aparece como autor del libro que resulta de esta colaboración (NAGI ZEKMI [2005] apud ORIZAGA DOGUIM, [2007]).

Orizaga argumenta, no entanto que, por seu caráter hibrido, mesclando biografia, etno-história, memória, crônica e outros gêneros, o texto acaba por abrir o leque para uma série de interpretações, como a de considerá-lo, por exemplo, como ficção autobiográfica, pela relação entre informante e escritora e pelo papel da protagonista com o texto.

Optamos, em nossa análise, por considerar nesse debate em torno da relação de Hasta no Verte Jesús Mio com a literatura em que a obra se encaixa, uma tendência contemporânea da literatura latino-americana à qual Josefina Ludmer denomina de pós-autonomia. De acordo com Ludmer, em "Identidades territoriais e produções do presente: literaturas pós-autônomas" (2013), é já ao fim do século XX que os textos literários na América Latina tendem a passar de uma estrutura e de características estéticas que indicam uma separação muito clara entre literatura e realidade - muito comum no experimentalismo moderno em alta na primeira metade do século - a uma inclinação que a autora denomina de pósautonomia. Essa tendência esmaece os limites claros estabelecidos para a literatura durante a primeira metade do mesmo século:

Em alguns textos do presente que atravessaram a fronteira literária (que chamamos de pós-autônomos), é possivel ver nitidamente o processo de perda da autonomia da literatura e as transformações que isso provoca. Cessam, formalmente, as classificações literárias, o que significa o fim das guerras, divisões e oposições tradicionais entre as formas nacionais e cos- mopolitas, formas do realismo e da vanguarda, da "literatura pura" e da "literatura social" ou comprometida, da literatura rural e urbana, assim como acaba a diferenciação literária entre realidade (histórica) e ficção. Já não é mais possivel ler esses textos com ou nesses termos; são as duas coisas, oscilam entre duas ou as desdiferenciam (LUDMER, 2013, p. 131).

A discussão em torno da relação do texto objeto de nossa análise com a literatura dialoga com uma questão fulcral para os estudos da área, que é o tema do cânone literário.

De acordo com Rita Terezinha Schimidt, em "Cânone, valor e a história da literatura: pensando a autoria feminina como sítio de resistência e intervenção" (2012) e "Centro e margens: notas sobre a historiografia literária" (2008), desde o século XVIII, estabeleceu-se uma separação entre o que deveria ser considerado cultura em contraposição à arte: "Enquanto o termo 'cultura' se referia a práticas tradicionais de caráter coletivo, o termo 'arte' foi associado ao objeto singularizado pelos processos de criação e sensibilidade individual" (2012, p. 59). Dessa separação, aponta Schimidt (2012, p. 59), teria derivado a noção das artes e, entre elas, da literatura enquanto objeto estético, o qual corresponderia a padrões de beleza universais pré-estabelecidos. É dessa noção do belo universal que derivariam, nesse conceito de literatura produzido então, as obras padrão, as grandes obras a partir das quais se pensaria o modelo de universalidade da literatura. Dessa mesma separação se teria originado o cânone literário e dela viria também a divisão entre a cultura erudita -aquela ligada ao valor estético, relacionada à noção de alta cultura- e cultura popular- ligada ao tradicional e à noção de cultura de massa.

Ocorre que, de acordo com Schimidt (2012, p. 60), destacadamente nos últimos trinta anos (e neste ponto a autora toca os apontamentos de Ludmer que citamos acima) houve um deslocamento da própria teoria da literatura em direção à interdisciplinaridade, em um movimento de desconstrução que passou a repensar a literatura e até mesmo as noções de tradição e de cânone: 
Pode-se dizer, que, do ponto de vista da teoria contemporânea, a doxa de um pensamento crítico pressuposto no valor intrínseco de textos definidos sob a rubrica "alta literatura" perde a hegemonia que detinha no passado na medida em que o literário passa a ser considerado uma categoria transitiva, fenômeno histórico contextualizado no campo das formas culturais, inserida, portanto, nos modos de produção material e práticas sociais historicamente especificas (SCHIMIDT, 2012, p. 61).

A partir daí, de acordo com a autora, se levanta inclusive o tópico da definição da própria noção do que seria uma literatura universal e de quem teria construído esse padrão a ser seguido já no século XVIII e a partir do qual se julgaria o que se aproxima e se distancia do texto com valor reconhecidamente literário.

Para Schimidt (2012, p. 61), a determinação do cânone literário é histórica e não pode ser analisada sem a observação desses dados:

Muitas das recentes reflexões sobre a história da literatura passam, necessariamente, pela compreensão da instituição literária e de seu papel histórico como instância reguladora, não só da definição do literário, mas também dos procedimentos de seleção e ordenamento de seus objetos na narrativa daquela história e dos discursos de valoração e interpretação que deram legitimidade à formação dos cânones literários nacionais.

Em reação a esses questionamentos sobre a literatura e a história e sobre a teoria da literatura instalaram-se dois pontos de vista contrários (SCHIMDT, 2012, p. 62-63). O primeiro demarcaria o problema da reorganização das noções relacionadas ao cânone em direção à massificação da arte por meio da globalização e à desvalorização da mesma. O segundo se embasa na multiplicidade de teorias que questionaram a noção de literatura ligada àquela conceituação que remete ao século XVIII. Este entendimento, ao se repensarem as relações entre literatura e cultura,

vai provocar deslocamentos importantes do ponto de vista da produção de conhecimento sobre o literário, questionando modelos e conceitos referenciais da cultura ocidental produzidos pelo pensamento eurocêntrico/ etnocêntrico/ patriarcal e expondo a pretensa universalidade de seu estatuto quando confrontado com novas formas de pensamento, de escritura e de subjetividade situados às margens das referidas tradições (SCHMIDT, 2012, p. 63).
Para o enfoque que propõe uma revisão da noção tradicional de literatura, tomamos a Lizandro Carlos Calegari, que, em "O cânone literário e as expressões de minorias: implicações e significações históricas", defende que é com os pós-estruturalistas e com os estudos culturais que se questiona uma noção básica que viria a incidir na própria noção de cânone: a verdade (CALEGARI, 2012, p. 29-30).

Partindo das considerações de Foucault, para quem a verdade estaria ligada diretamente a conceitos produzidos a partir de relação de poder, o autor aponta que se desenvolveram tanto estudos culturais quanto estudos feministas e pós-coloniais que culminaram, no campo da literatura, no questionamento da própria noção de cânone enquanto uma verdade. O cânone, afirma o autor (2012, p. 30), deixou, assim como a verdade, de representar uma noção universal, passando a ser considerado uma expressão das relações de poder e, com isso, se passou a questionar o padrão de universalidade da literatura.

Calegari aponta ainda (2012, p. 30), citando Roberto Reis, que a própria noção de cânone, que embasa a universalidade, pressupõe uma noção de seleção e exclusão. Em seu texto, a partir do qual Calegari disserta, Reis afirma:

\begin{abstract}
[...] o conceito de cânon implica um principio de seleção (e exclusão) e, assim, não pode se desvincular da questão do poder: obviamente. os que selecionam (e excluem) estão investidos da autoridade para fazê-lo e o farão de acordo com os seus interesses (isto é: de sua classe. de sua utilidade). Convém atentar ainda para o fato de que o exercício dessa autoridade se faz num determinado espaço institucional (REIS, 1992, p. 70).
\end{abstract}

Em "Canon", Roberto Reis ainda se aprofunda mais na matéria e, antes de dissertar sobre a noção de cânone a partir da qual se constitui o universal literário, problematiza o processo de formação de culturas e a tradução da cultura na forma de linguagem. O crítico aponta que a linguagem é parte essencial do processo de seleção ideológica de noção de cultura pelas classes dirigentes:

[...] a escrita sempre foi uma forma de poder. Nas sociedades humanas o escriba e o sacerdote eram poderosos ali estavam a serviço do 
poder, da mesma forma que, nas sociedades pós-industriais, o monopólio da informação através dos meios de comunicação de massa desempenha um papel fundamental no que tange à dominação social (REIS, 1992, p. 67).

Baseando-se em Reis, Calegari (2012, p. 30) acrescenta que, embora se intente julgar uma produção sob um critério puramente estético, ligado à noção de literariedade, sem qualquer relação com critérios externos, todo o texto literário é produzido em dado tempo histórico e social de maneira que segue critérios de literariedade também embasados em escolhas discursivas que o cercam e que estão iniludivelmente ligadas ao poder.

Ressaltamos que não há a pretensão neste texto de aproximar, afastar ou mesmo categorizar a obra que aqui analisamos levando em conta uma noção de cânone - seja a tradicional, ligada à noção do belo universal ou quaisquer outras que estejam em voga na contemporaneidade, mesmo a partir das reflexões aqui expostas. Interessa, ao trazer essas questões para as várias classificações agregadas a Hasta no verte Jesús mío, ponderar que a própria opção por aproximar ou distanciar a obra do literário passa por uma série de escolhas discursivas que envolvem as considerações sobre o cânone e a universalidade de textos literários, de forma que, ao optar por classificar o texto de Poniatowska como novela testimonial, bildungsroman ou testimonio feminino, passaria por também realizar uma série de escolhas discursivas que não corresponderiam ao nosso ponto de vista.

Tornando ao texto em análise, reconhecemos sua natureza hibrida, já que há nuances que impedem que o texto seja considerado uma ficção - como aquelas da primeira metade do século XX de que nos fala Josefina Ludmer, dotadas de contornos claros que as distanciam do real - e consideramos que a própria noção de texto literário a partir da qual Hasta no verte Jesús mío poderia ser categorizado tem passado por revisões.

Com base nesses dois apontamentos, consideramos o nosso objeto de estudo um texto da tendência da pós-autonomia, compreendendo no entanto que, assim como as outras aproximações feitas a respeito do nosso objeto de estudo, esta escolha passa também por conceituações concebidas a partir de novas verdades e, dialogando com Calegari (2002) e Reis (1992), observamos que essas mesmas verdades são constituídas a partir de escolhas discursivas orientadas por determinadas relações de poder e podem, portanto, ser questionadas e descontruidas.

Aproveitamo-nos disso para demonstrar como nesse texto há ainda uma possibilidade, para além daquela que representa sua própria estrutura, de questionar padrões universais por meio da passagem da experiência individual à coletiva em que se traduz a passagem da experiência de Josefina Bórquez à experiência de Jesusa Palancares no texto de Elena Poniatowska.

Vale ressaltar que não nos referimos aqui à noção de experiência exatamente como a exposta por Walter Benjamin em "Experiência e pobreza" e em "O narrador", quer dizer, como algo comunicado aos jovens pela autoridade da velhice (BENJAMIN, 1985, p. 114) algo que, por sorte de semelhanças entre aquilo que é contado e o que é vivido poderia gerar efeitos para a produção de um futuro (JAY, 2009, p. 380). Aquela experiência que, perdendo espaço, de acordo com Benjamin, desde o nascimento do romance, ter-se-ia tornado emudecida e indizivel pela experiência da primeira guerra mundial, e dado lugar a narrativas coletivas e ao bombardeamento de informações que se produziriam no durante a guerra e no periodo pós-guerra, em um processo se separação entre corpo e narração, que esvaziaria a experiência de seu sentido (SARLO, 2007, p. 29).

Referimo-nos aqui à experiência retomada em meados do século $X X$, que, tendo-se tornado alienada da arte e da literatura de forma muito clara na primeira metade do século, no periodo que, na literatura, Josefina Ludmer (2013) associa à autonomia, retorna ao campo das artes, juntamente com a noção de sujeito, não agora como incontestável, mas como forma de expor o real como problema, de olhar de forma desconfiada e colocar o real em análise (GARRAMUÑO, 2009, p. 103-104). 


\section{De Josefina Bórquez a Jesusa Palancares}

Retomemos o enredo de Hasta no verte Jesús mío: Jesusa, uma oaxaquenha de origem pobre e ascendência indígena, inicia sua narração no momento em que, na Obra Espiritual, religião à qual pertence, entra em contato com toda a sua familia já morta e com suas origens, que remontam a outras encarnações e, partindo desse ponto, relata sua vida desde os primeiros anos de sua existência. Daqueles tempos, os primeiros anos, a personagem narra a perda da mãe e a sua tutela e dos irmãos pelo pai e pelas madrastas até o início da Revolução Mexicana. Um novo tempo se inaugura quando Jesusa parte com seu pai e outros combatentes em expedição. Da sublevação, a personagem conta a rotina das soldaderas, a relação com o pai e o casamento com o soldado Pedro, sempre permeando suas memórias com os acontecimentos históricos da Revolução, a partir de seu ponto de vista. De seu periodo pós-revolucionário, a personagem, que se torna viúva ainda em seus vinte anos, narra sua reintegração à sociedade, seu trabalho em casas de familias de classes mais elevadas que a sua, em estabelecimentos comerciais e fábricas e o desenvolvimento de sua fé, ligada ao espiritismo, que ela denomina Obra Espiritual.

Em todo esse percurso, notam-se acontecimentos individualizados da vida da personagem, como a morte de sua mãe:

\begin{abstract}
No sé si la causa era la pobreza o porque asi se usaba, pero el entierro de mi madre fue muy pobre. La envolvieron en un petate y vi que la tiraban asi nomás y que la echaban tierra encima. Yo me arrimé junto a mi papá pero estaba platicando y tomando sus copas con todos los que lo acompañaron y no se dio cuenta cuando me aventé dentro del pozo y con mi vestido le tapé la cabeza a mi mamá para que no le cayera tierra en la cara (PONIATOWSKA, 1969, p. 17).
\end{abstract}

Na passagem está um narrador, em primeira pessoa, retomando os primeiros momentos de sua vida. Nele vemos a origem humilde de Jesusa e o que a levou a ficar sob a tutela de seu pai, motivo pelo qual experienciou não só a convivência com várias madrastas, mas também uma participação prematura no Levante Mexicano de 1910. A mesma participação que a faria concretizar seu primeiro e único casamento.
A presença dos acontecimentos históricos que atravessam sua história, como a tomada da capital do México por Madero, 1911, quando Jesusa lá vivia com sua madrasta Evarista, que trabalhava em um presídio feminino, está exemplificada nos excertos: "En 1911, Madero tomó la ciudad capital de México y fue entonces cuando ocurrió el temblor y se cayeron muchos edificios. Tembló a las cuatro de la mañana. Yo estaba solita con la presa nomás" (PONIATOWSKA, 1969, p. 37). E, ainda:

\begin{abstract}
Habia mucho ruido. Toda la gente se hincó por fuera, en la banqueta, en el patio, por el rio, por el campo, por el monte, entre las tescaleras y los huizaches, en donde andaban ya milpeando de madrugada, haciendo su quehacer. En México dicen que el temblor duró un cuarto de hora, la tierra toda alrevesada, la tierra aventaba las casas encabronada. En Tehuantepec quién sabe, pero fue muy terrible y se estrelló la cárcel (PONIATOWSKA, 1969, p. 38).
\end{abstract}

Registra-se também a ocorrência de impressões sobre caracteristicas sociais do tempo e espaço das memórias:

\begin{abstract}
En aquellos años del Señor las madrinas eran las que pedian al niño antes de que naciera. Veian a la mamá que estaba enferma y si les pintaba bien el parto, luego le preguntaban:

- ¿Me va a regalar su niño o niña para que la lleve a bautizar?

A los niños los presentaban al templo antes de los cuarenta dias con un ropón grande, bonito, de holanes que arrastrara hasta el suelo, y a esa sacada le decian "sacamisa". La madrina llevaba al chilpayate y a la mamá para que los fuera conociendo la Virgen en recuerdo de cuando ella llevó a su hijo con Zacarias (PONIATOWSKA, 1969, p. 46).
\end{abstract}

De acordo com Ana Costa (2001, p. 132-133) na representação do sujeito, a escrita em si é uma maneira de transformar a experiência, de fazêla transbordar, pulsar do eu e é a possibilidade de passagem da pessoalidade à cultura. 0 que provocaria essa transformação seriam os restos, os detritos que ligam o eu ao outro, ou seja, traços de experiência que encontrariam correspondências no coletivo.

Ao narrar suas experiências, atravessando contextos históricos e sociais, como nas duas últimas citações, ou mesmo questionando uma realidade em que a experiência toma corpo, 
como na primeira, da morte de sua mãe, o eu de Jesusa pulsa com o outro, e, nos detritos do real que expõe, apresenta similitudes com experiências coletivas.

Essa experiência individual que passa ao coletivo se evidencia na própria escrita da narração. De acordo com Ana Costa (2001, p. 134), os detritos, os restos não assimiláveis daquele que escreve são, de certa forma, transportados pela escrita no ato de escrever, ou seja, ao escrever, o autor tenta atribuir um registro, aquilo que se inscreve no corpo na interação com o outro (KEHL, 2001, p. 14), ao seu texto. Nesse ato então, de repetição e produção, é que se formaria um estilo:

O estilo é algo que se repete. É a insistência de algo que não se escreve, nesses detritos que são impossiveis de escrever e de transmitir. Quer dizer que é isso que, de alguma maneira, produz efeitos no leitor para além do argumento ou do entendimento daquilo que ele lê. E produz efeitos no autor, para além daquilo que ele pode reconhecer escrevendo (COSTA, 2001, p. 134).

Hasta no verte Jesús mío apresenta uma forma de narrar que, de acordo com Cynthia Steele (1992, p. 158), é a de um texto que exibe um forte aspecto regionalista da lingua espanhola. Isso fica claro, de acordo com a autora, pelo fato de que Poniatowska teria buscado a inspiração nos dialetos de várias trabalhadoras domésticas da república, para além da inspiração em Josefina Bórquez, para a produção do texto.

Essa construção de um estilo de aspecto regionalista da língua é ainda realçada enquanto possibilidade quando a autora fala de sua experiência com Jesusa:

En su voz oía yo la voz de la nana que me enseñó español, la de todas las muchachas que pasaron por la casa como chiflonazos, sus expresiones, su modo de ver la vida, si es que la veian porque solo vivian al dia, no tenian razón alguna para hacerse ilusiones.

Estas otras voces de mujeres marginadas hacian coro a la voz principal, la de Jesusa Palancares, y creo que por eso en mi texto hay palabras, modismos y dichos que provienen no solo de Oaxaca, el estado de Jesusa. Sino de toda la República, de Jalisco, de Veracruz, de Guerrero, de la sierra de Puebla (PONIATOWSKA, 2001, p. 22).
Tem-se na afirmação de Poniatowska a compreensão do texto em análise, essa narração em primeira pessoa de uma mulher que ocupa uma posição de marginalidade social, como uma escrita configurada em um estilo. Esse estilo teria contornos não de um eu individualizado, mas de um grupo de pessoas, ou melhor, do grupo de mulheres marginalizadas - babás, empregadas domésticas e mulheres que trabalham em outras profissões pouco valorizadas social e economicamente- que, apesar de suas diferenças individuais, apresentariam traços em comum, entre os quais a linguagem, identificáveis em todo o território da República.

Além disso, é válido lembrar para a construção do estilo que a escrita de Hasta no Verte Jesús Mio é resultado de uma interpretação materializada na escrita, a de Poniatowska, feita a partir de entrevistas a uma outra mulher, Josefina Bórquez, que, ao transformar sua experiência em linguagem, faz ela mesma uma interpretação da sua realidade vivida.

Isso, por si só, já conteria resquícios da imaginação e de novas temporalidades. Para melhor explicitar a afirmação, recorremos a dois pontos-chave do texto "Crítica do testemunho: sujeito e experiência" (2007), de Beatriz Sarlo. O primeiro deles é o fato de, segundo a autora, ser a imaginação aquilo que colocaria em ordem as experiências para transformá-las em linguagem, estabelecendo as conexões que se fazem necessárias para que o sentido seja completo (SARLO, 2007, p. 41). O segundo seria o fato de que a linguagem, ao mesmo tempo em que transforma a experiência em comunicação, insere-a sempre em uma nova temporalidade, a cada repetição, atualizando-a (SARLO, 2007, p. 24-25).

Em complemento a isso, retomamos o texto "Cânon", de Roberto Reis, desta vez para falar sobre a questão da passagem da realidade à linguagem. $O$ autor faz duas considerações que são úteis em nossa análise. A primeira delas é que todo leitor é marcado por uma série de noções pré-concebidas que, no ato da leitura, acabam por atritar com o texto para produzir interpretação (REIS, 1992, p. 65). A segunda é 
que a linguagem, ao significar o real, o organiza, porque o transforma em signo, mas também o falseia, porque faz de todas as possibilidades de algo uma só ao comunicar algo, apontando direcionamentos discursivos para a realidade como ela é (REIS, 1992, p. 66-67).

Dessa forma, dialogando com Ludmer (1996), podemos afirmar que os detritos do real da narração original de Josefina sofrem primeiro interferência da imaginação dessa narradora primeira, ao serem transformados em linguagem no contar oral da Oaxaquenha a Poniatowska. Nessa primeira interferência da narradora, a experiência é inserida em influências de uma nova temporalidade, aquela do presente das entrevistas orais. Em seguida, a narração oral, ao ser transformada em texto escrito sob a interferência de Poniatowska, é inserida em uma outra temporalidade, agora aquela da escrita da autora, contando aí com as interferências desse novo contexto.

Além disso, dialogando com Reis (1992), podese propor uma leitura que leve em conta as noções pré-concebidas que Josefina Bórquez faz de sua realidade e que, ao transformar-se em linguagem, sua narração é organizada em escolhas discursivas. O mesmo aconteceria com a leitura feita por Poniatowska da narração oral de Bórquez, de forma que se inseririam na escrita as noções pré-concebidas da própria autora sendo somadas a ela novas escolhas discursivas.

Jesusa passa então de um eu individualizado a uma representação de outro sentido maior representado pela sua narração. Ocorre aí um processo proposto por Walter Benjamin e exposto por Ana Costa (2001, p. 145). A linguagem, afirma Costa (2001, p. 145), possui um aspecto nomeante e um aspecto instrumental. $O$ interesse primário do homem seria o aspecto instrumental, o "de ser um veículo de comunicação de um sentido", de atribuir uma imagem e uma interpretação a algo por meio da linguagem. Por conta disso, o aspecto nomeante, aquele em que a linguagem significaria em si, perderia força, de forma que o processo de nomear algo para personificá-lo não teria mais o sentido que se pretende, já que já existe nessa nominalização a veiculação de um sentido.
Algo semelhante ocorre a Jesusa. Ela já não é aquele eu do qual se origina a narração. Ela passa a representar um novo sentido enquanto personagem. Um sentido que está impresso em sua escrita, nas passagens de sua história, na sua construção enquanto personagem feminina, mexicana, soldadeira, de classe baixa, e em diálogo com uma espiritualidade. Há ai uma passagem de eu individuo ao eu grupo, e, arriscamos dizer, o eu representativo de uma minoria.

Essa afirmação é fortalecida pelo próprio nome da personagem. O nome de Jesusa a desloca da identificação única com Josefina Bórquez e a coloca no campo do coletivo por duas relações. Uma que estabelece uma conexão com a figura do Jesus cristão e outra que a identifica com a mulher comum.

A associação de "Jesusa" ao Jesus da crença cristã, se estabelece nestes termos: Jesusa é uma mulher que, no percurso de sua existência, auxilia vários individuos que cruzam seu caminho, como crianças sem familia, idosos desamparados, mulheres ameaçadas e amigos doentes, tomando por isso, contornos de um ideal pregado pelo cristianismo.

Na sua identificação com a mulher comum, "Jesusa", ao mesmo tempo que remete a um personagem do imaginário cristão, é uma mulher de meia idade, que bebe exageradamente e que, principalmente em sua juventude, tinha temperamento forte e explosivo, e estava disposta a enfrentar conflitos e a apresentar comportamentos muito distantes daqueles pregados pela religião, configurando uma oposição ao ideal cristão, principalmente no que tange ao feminino.

O titulo e a capa da obra reforçam essa noção de coletividade que carrega o nome do personagem. (Melhor juntar este e o próximo parágrafo)

O título Hasta no verte Jesús mío é uma referência à expressão "hasta verte, Jesús mio". Tal expressão deriva do costume de frades consumirem, em refeitórios de conventos, um vinho que tinha os dizeres "hasta verte, Jesús mío" no fundo da garrafa. Para ver o que estava impresso era necessário beber todo o líquido de uma garrafa. Essa ação teria com o correr do tempo passado para o uso popular, de maneira 
que em muitas casas o que se via era o consumo de vinho até que se visse sua base para que se pudesse ver as mesmas inscrições ao fundo (MONTORO DELARCO, 2018, p. 136). Esse costume remeteria então a uma memória coletiva.

Assim como essa forma de consumir vinhos, o nome da obra remete ele também a uma coletividade, mas desta vez uma coletividade representada na figura Jesusa, sendo ela também, assim como o costume de beber garrafas inteiras de vinho para ver inscrições sagradas ao fundo, uma representação de conexões com a noção santidade e com a vida de uma pessoa comum, como já detalhamos anteriormente.

A capa da edição de que dispomos para análise (Ediciones Era, 1985) contém a figura do Menino Jesús de Atocha. De acordo com a história cristã, essa figura ajudou os cristãos espanhóis em situação de penúria durante a querela entre muçulmanos e cristãos no século XII, em Espanha. $O$ auxilio teria vindo por meio da figura de um menino de doze anos que teria ajudado os cristãos, que se encontravam sob a custódia de muçulmanos, dando-lhes todas as noites comida para que não passassem fome (BALL; HINOJOSA, 2019).

Essa mesma referência é apresentada no livro. Jesusa presencia uma história semelhante à do menino Jesus de Atocha do imaginário cristão, quando uma encarcerada do presídio em que a protagonista vivia em sua infância é ajudada por um menino misterioso:

\begin{abstract}
La presa estaba haciendo el novenario al Niño de Atocha y todos los dias pedía caridad y todos le daban su tlaco de limosna... Faltaban dos o tres dias para que se cumpliera el novenario cuando de repente llegó un niño de unos seis o siete años con una canasta en la mano y gritó el nombre de ella para que le pasaran la canasta. Como no tenía a nadie que se acordara de ella, se sorprendió. El niño siguió llevándole el desayuno en la mañana y a los tres dias también le dejó la comida. Nosotros le recibiamos la canasta porque creíamos que era niño de a deveras, un cristiano, porque así lo vimos: niño (PONIATOWSKA, 1969, p. 39).
\end{abstract}

O Niño de Atocha que aparece no texto, assim como aquele da história original, representa na verdade apenas uma ideia genérica de um menino de aparência simples que vem para ajudar uma pessoa ou um grupo e que poderia ser identificado com qualquer menino em condições similares e na mesma faixa etária. Ele deixa de ser uma pessoa no imaginário de quem o vê e passa a ser veículo de um novo sentido. No caso da presa, por exemplo, esperança. Essa mesma passagem do individual à representação de um simbólico coletivo ocorre a Jesusa.

\section{Considerações finais}

Assim, tornamos a afirmar que Jesusa é então "marca", no sentido de ser representação de outra coisa que não o nome personificado, como veículo de um novo sentido, por conta dessa representação, que carrega resquícios de marginalidade pela classe social que representa em estilo e narração, pela representação do feminino que é, ao mesmo tempo, desvio e pertencimento e por sua construção enquanto resultado de um contexto histórico que representa.

O fato de Jesusa estar representada em uma narração em primeira pessoa, de deixar de ser o observado, para se corporificar por meio de experiências na narração é por si só um questionamento do real que representa pela exposição que seu narrador faz de um contexto social visto a partir de um olhar marginalizado e por todas as opressões e todas as variantes históricas e sociais que a perpassam. Além disso, o texto é também um questionamento aos próprios limites impostos à literatura e sua representação do real e das noções cristalizadas de ideal estético e cânone.

Acreditamos dessa forma que a obra desempenha um papel semelhante ao de várias obras de seu tempo segundo Florencia Garramuño (2009, p. 6990): o que antes ficaria à margem das artes em geral e da literatura coloca-se como seu centro, retirando essas artes de seu espaço institucionalizado, desauratizando-as e questionando aí também os seus limites enquanto arte. Ressaltamos enfim que, enquanto narração de experiência, a obra de Poniatowska que aqui discutimos apresenta-se como mais um entre os vários motivos pelos quais esse debate se faz importante. 


\section{Referências}

ALBIN, Maria C. El bildungsroman femenino en femenino en Hasta no verte Jesús mío de Elena Poniatowska. América sin Nombre, Alicante, n. 12, p. 21-28, dic. 2008. https://doi.org/10.14198/ amesn2008.11-12.07

BALL, Ann; HINOJOSA, Damien. El santo niño de atocha. Disponivel em: http://www.ninoatocha.com/ history.html. Acesso em: 24 jul. 2019.

BENJAMIN, Walter. Experiência e pobreza. Magia e Técnica, Arte e Política. São Paulo: Brasiliense, 1985

CALEGARI, Lizandro Carlos. O cânone literário e as expressões de minorias: implicações e significações históricas. REVELL: Revista de Estudos Literários da UEMS, Campo Grande, ano 3, v. 2, n. 5, p. 29-44, dez. 2012.

COSTA, Ana. Da representação social da memória. In: COSTA, Ana. Corpo e escrita: relações entre memória e transmissão da experiência. Rio de Janeiro: Relume Dumará, 2001. p. 123-168.

GARRAMUÑO, Florencia. La experiencia opaca: literatura y desencanto. Buenos Ayres: Fondo de Cultura Económica, 2009.

JAY, Martin. El lamento por la crisis de la experiencia: Benjamin y Adorno. In: JAY, Martin. Cantos de experiencia: variaciones modernas de un tema universal. Buenos Aires: Paidós, 2009. p. 365-415. https://doi. org/10.22201/fcpys.2448492xe.1999.176.49008

KEHL, Maria Rita. Inscrever para lembrar, escrever para esquecer. In: COSTA, Ana. Corpo e escrita: relações entre memória e transmissão da experiência. Rio de Janeiro: Relume Dumará, 2001. p. 11-24.

LUDMER, Josefina. Identidades territoriais e produção de presente: Literaturas pós-autônomas. In: LUDMER, Josefina. Aqui América Latina: Uma especulação. Tradução de Rômulo Monte Alto. Belo Horizonte: UFMG, 2013. p. 127-133. https://doi. org/10.25025/perifrasis20189.17.07

MONTORO DEL ARCO, Esteban. El porque de los dichos: la fraseología del vino. Disponivel em: https://www.researchgate.net/publication/28139067_El_porque_de_ los_dichos_la_ fraseologia_del_vino. Acesso em: 01 jul. 2018. https:// doi.org/10.35376/10324/22566

ORIZAGA DOGUIM, Daniel. Hasta no verte Jesús mí: la voz del otro, voz propia. Disponivel em: https:// critica.cl/literatura/hasta-no-verte-jesus-mio-la-voz-del-otro-voz-propia. Acesso em: 23 jul. 2019. https://doi.org/10.2307/4530622

PONIATOWSKA, Elena. Hasta no verte Jesús mio. México D. F.: Ediciones Era, 1985. Livro não paginado.

PONIATOWSKA, Elena. Vida y muerte de Jesusa (1) In: PONIATOWSKA, Elena. Luz y Luna, las lunitas. Tafalla: Txalaparta/Ediciones Era, 2001. p. 7-47.

REIS, Roberto. Cânon. In: REIS, Roberto; JOBIM, José Luís (org.) Palavras da critica: tendências e conceitos no estudo da literatura. Rio de Janeiro Imago, 1992. p. 65-92.
SARLO. Beatriz. Critica do testemunho: sujeito e experiência. In: SARLO. Beatriz. Tempo passado: cultura da memória e guinada subjetiva. Tradução de Rosa Feire D'Aguiar. São Paulo: Companhia das letras, 2007. p. 23-44. https://doi.org/10.18542/rmi.v4i5.2797

SCHIMIDT, Rita Terezinha. Centro e margens: notas sobre a historiografia literária. Estudos de literatura brasileira contemporânea, Brasília, DF, n. 32, p. 127141, jul./dez. 2008.

SCHMIDT, Rita Terezinha. Cânone, valor e história da literatura: pensando a autoria feminina como sitio de resistência e intervenção. El hilo de la fabula, Santa Fe, n .12, p. 59-72, 2012. https://doi.org/10.14409/ hf.voi12.4695

SCHUESSLER, Michael K. Elenisima: Ingenio y figura de Elena Poniatowska. Ciudad de México: Penguin Random House Grupo Editoral, 2017. Livro não paginado.

SKLODOWSKA, Elzbieta. Miguel Barnet: Hacia la poética de la novela tesimonial. Disponivel em http:// www.jstor.org/stable/4530370. Acesso em: 16 nov. 2019. https://doi.org/10.2307/4530370

STEELE, Cynthia. Testimonio y autor/idad en "Hasta no verte Jesús mio," de Elena Poniatowska. Disponível em http://www.jstor.org/stable/4530628. Acesso em: 16 nov. 2019. https://doi.org/10.2307/4530628

\section{Endereço para correspondência}

Mariana Marise Fernandes Leite

Av. Fernando Ferrari, 514

Goiabeiras, 29075-910

Vitória, ES, Brasil

\section{Mariana Marise Fernandes Leite}

Graduada em Letras Português pela Universidade Federal do Espirito Santo (Ufes) e Mestre em Letras pelo Programa de Pós-Graduação em Letras da mesma instituição (PPGL), doutoranda do Programa de Pós-graduação em Letras da Universidade Federal do Espírito Santo (PPGL - Ufes), bolsista da Fundação de amparo à Pesquisa e Inovação do Espírito Santo (FAPES) e membra do grupo de estudos "Mulheres com todas as letras" vinculado à Ufes. 